\title{
The Role of Augmented Intelligence (AI) in Detecting and Preventing the Spread of Novel Coronavirus
}

\author{
Justin B. Long ${ }^{1}$ - Jesse M. Ehrenfeld ${ }^{2}$ \\ Published online: 4 February 2020 \\ (C) Springer Science+Business Media, LLC, part of Springer Nature 2020
}

In late 2019, a novel coronavirus was identified - 2019-nCoV [1]. This is likely the third time in three decades that a zoonotic coronavirus has jumped from infecting animals to humans [2]. As of today, 213 have died and 9809 have been infected in China with the center of the outbreak being located in Wuhan but now having spread, with confirmed cases twenty-two other countries [3]. While the fatality rate of 2019-nCoV is less than other recent respiratory virus outbreaks, it remains much higher than other commonly encountered causes of respiratory infection but its full impact is yet undetermined [4]. The World Health Organization (WHO) has now declared the coronavirus outbreak to be a public-health emergency of international concern.

While augmented intelligence (AI) in healthcare has been widely cited as an important approach to aid in the detection of disease and making clinical diagnosis, this recent outbreak emphasizes the need and opportunity to utilize AI to predict outbreaks. While the use of expert epidemiologists and public health officials cannot be replaced, AI can serve to compile rapidly evolving information to assist public health experts in complex decision-making. Aggregation of social media, news media, rapidly evolving health reports, and other disparate data is a daunting task which AI is poised to overcome. During prior outbreaks, such as Severe Acute Respiratory Syndrome (SARS) in China in 2003, little real-time data was available [5]. Now there is an explosion of available data and

This article is part of the Topical Collection on Editorials

Jesse M. Ehrenfeld

jehrenfeld@mcw.edu

Justin B. Long

justin.bradley.long@emory.edu

1 Children's Healthcare of Atlanta at Egleston, Emory University, Atlanta, GA, USA

2 Advancing a Healthier Wisconsin Endowment, Medical College of Wisconsin, Milwaukee, WI, USA the tools utilized presently must meet that and overcome the challenge of big data.

$\mathrm{AI}$ is not necessarily new to epidemiology. For instance, one group monitoring the informal data sources in the 2019nCoV outbreak is HealthMap. HealthMap is comprised of a team of researchers, epidemiologists, and software developers at Boston Children's Hospital that is a leader in monitoring informal sources for disease outbreaks and evaluating emerging public threats [6]. While AI shows promise in the area of aggregation of big data for use in epidemiologic trending, there have been notable failures as well. One well-known example is Google Flu, which utilized search engine queries to improve flu epidemic tracking. The model famously underperformed but this was likely due to poor design of the variables used for prediction [7]. Since then, other researchers have used the Google's data and other social media data to much more accurately predict the spread of influenza [8].

BlueDot, a Canadian-based AI company specializing in infectious disease epidemiology, predicted the 2019-nCoV outbreak and sent alerts to its customers on December 31 . The Centers for Disease Control and Prevention (CDC) had not warned of the outbreak until January 6 and the first WHO warning was January 9 [9]. BlueDot has shown previous success as well in prediction of the international spread of Zika virus from Brazil [10]. During any outbreak, the speed of information gathering and information dissemination is critical to containment of the threat [11]. The work published by the authors from BlueDot demonstrates the high variety and veracity of data that can be aggregated to make very accurate epidemiologic predictions utilizing AI.

There are other important applications of AI to the ongoing outbreak of 2019-nCoV. Though none have yet been officially announced, AI may assist in development of more accurate symptom checking in order to predict the likelihood of new infection with 2019-nCoV versus other, more benign causes of respiratory illness. AI may be applied to treatment records in order to more quickly home in on the most effective treatment regimens as different approaches are attempted and 
documented. And, early detection of geographical containment in certain regions that outpace modeled expectations may reveal more effective techniques for containment through near real-time detection of differences in practice.

The 2019-nCov will not be the last epidemic to challenge public health experts. The growth of AI-driven techniques to identify epidemiologic risks early will be key to our improvement of prediction, prevention, and detection of future global health risks. The devastating situation in Wuhan, China and future epidemics will also find value in ongoing research in 2019-nCov case detection, spread prediction, treatment effectiveness, and containment. The wide variety, velocity, and veracity of data now available in crises yield data sets that many researchers will now need to incorporate into evermore complex models. This requires expansion of talent within AI for healthcare applications. AI is no longer a niche research area nor is it a tool for the most advanced healthcare systems only, its global impact on healthcare is real and its potential to save lives in this epidemic as well as future epidemics should not be underestimated. It is critical to the global health of all humankind for the scientific community to embrace AI and leverage its power in securing our collective future.

\section{References}

1. Zhu, N., Zhang, D., Wang, W., et al. A Novel Coronavirus from Patients with Pneumonia in China, 2019. N Engl J Med. Jan 24 2020.

2. Mahase E. China coronavirus: what do we know so far? BMJ. Jan 24 2020;368:m308.
3. Coronavirus spreads to more countries, All the latest updates: $\mathrm{Al}$ Jazeera Media Network. https://www.aljazeera.com/news/2020/01/ clone of clone of clone of clone of china-battles-corona200130230453300.html. Published 2020. Accessed January 31, 2020.

4. Paules CI, Marston HD, Fauci AS. Coronavirus Infections-More Than Just the Common Cold. JAMA. Jan 232020.

5. Ross C. In coronavirus response, $\mathrm{AI}$ is becoming a useful tool in a global outbreak, data experts say: STAT News. https://www. statnews.com/2020/01/29/coronavirus-response-artificialintelligence-becoming-useful/. Published 2020. Accessed January $31,2020$.

6. About HealthMap: The Disease Daily. http://www.diseasedaily.org/ about. n.d. Accessed January 31, 2020.

7. Lazer D, Kennedy R. What We Can Learn From the Epic Failure of Google Flu Trends: WIRED. https://www.wired.com/2015/10/canlearn-epic-failure-google-flu-trends/. Published 2015. Accessed January $31,2020$.

8. Brooks, L. C., Farrow, D. C., Hyun, S., Tibshirani, R. J., and Rosenfeld, R., Nonmechanistic forecasts of seasonal influenza with iterative one-week-ahead distributions. PLoS Comput Biol. 14(6): e1006134, 2018.

9. Niller E. An AI Epidemiologist Sent the First Warnings of the Wuhan Virus: WIRED. https://www.wired.com/story/aiepidemiologist-wuhan-public-health-warnings/. Published 2020. Accessed January 31, 2020.

10. Bogoch, I. I., Brady, O. J., Kraemer, M. U. G., German, M., Creatore, M. I., Kulkarni, M. A., Brownstein, J. S., Mekarus, S. R., Hay, S. I., Groot, E., Watts, A., and Khan, K., Anticipating the international spread of Zika virus from Brazil. Lancet. 387(10016): 335-336, 2016

11. Phelan AL, Katz R, Gostin LO. The Novel Coronavirus Originating in Wuhan, China: JAMA. https://jamanetwork.com/journals/jama/ article-abstract/2760500. Published 2020. Accessed January 31, 2020.

Publisher's Note Springer Nature remains neutral with regard to jurisdictional claims in published maps and institutional affiliations. 